\title{
EROSÃO HÍDRICA INFLUENCIADA POR UMA APLICAÇÃO DE DEJETO LÍQUIDO DE SUÍNOS NO SOLO CULTIVADO EM SEMEADURA DIRETA ${ }^{(1)}$
}

\author{
José Mecabô Júnior ${ }^{(2)}$, Ildegardis Bertol ${ }^{(3)}$, Fabrício Tondello Barbosa ${ }^{(4)}$ \& Gabriel de \\ Souza Oselame ${ }^{(5)}$
}

\section{RESUMO}

\begin{abstract}
A suinocultura em Santa Catarina é responsável por geração de emprego no meio rural e, por isso, apresenta grande importância social e econômica. Este trabalho foi realizado entre março e setembro de 2012 para avaliar a influência de uma aplicação de dejeto líquido de suínos na erosão hídrica, em um Nitossolo Bruno aluminoférrico húmico, nos tratamentos constituídos pelas doses: 0; 50; 100; e $200 \mathrm{~m}^{3} \mathrm{ha}^{-1}$ do dejeto aplicado na superfície do solo uma única vez, 30 dias após a germinação da aveia-preta. As parcelas tinham $11 \times 3,5 \mathrm{~m}$ e declividade média de $14,4 \%$. Ao longo do ciclo da aveia, foram realizados quatro testes de chuva simulada, cada um com quatro chuvas com intensidade planejada de $65 \mathrm{~mm} \mathrm{~h}^{-1}$ e duração de $75 \mathrm{~min}$, com simulador de chuva tipo Swanson. As perdas totais de solo e água por erosão hídrica não foram influenciadas pela dose de dejeto líquido de suínos aplicado sobre o solo cultivado com aveia, evidenciando, no entanto, influência do teor de água no solo antecedente às chuvas simuladas aplicadas. Os teores de $\mathrm{P} \mathrm{e} \mathrm{K}$ solúveis na água da enxurrada diminuíram após a aplicação de dejeto líquido de suínos no solo cultivado com aveia, por certo tempo; quando o cultivo foi submetido à chuva simulada, os teores reduziram nas chuvas do teste 1 para as do teste 3 e aumentaram nas do teste 4 . Os teores de $\mathrm{P}$ e K solúveis na água da enxurrada diminuíram com a dose de $100 \mathrm{~m}^{3} \mathrm{ha}^{-1}$ de dejeto líquido de suínos aplicado sobre o solo para a dose zero $\mathrm{m}^{3} \mathrm{ha}^{-1}$, nas chuvas simuladas dos testes 1 e 2. As perdas totais de $\mathrm{Pe} \mathrm{K}$ solúveis na água da enxurrada não foram influenciadas pela dose de dejeto líquido de suínos aplicado sobre o solo no cultivo da aveia; no entanto, apresentaram tendência de diminuir nas chuvas do teste 1 para as do teste 3 e de aumentar naquelas do teste 4 . Os teores de $\mathrm{P}$ e $\mathrm{K}$ solúvel na água da enxurrada reduziram exponencialmente com a elevação do número de teste de
\end{abstract}

\footnotetext{
(1) Parte da Dissertação de Mestrado do primeiro autor. Recebido para publicação em 3 de setembro de 2013 e aprovado em 16 de junho de 2014.

(2) Mestrando em Ciência do Solo, Centro de Ciências Agroveterinárias, Universidade do Estado de Santa Catarina - CAV/ UDESC. Av. Luis de Camões, 2090. CEP 88520-000 Lages (SC). E-mail: josemecabo@yahoo.com.br

(3) Professor, Departamento de Solos e Recursos Naturais, CAV/UDESC. Bolsista PQ/CNPq. E-mail: a2ib@cav.udesc.br

(4) Professor, Departamento de Solos e Recursos Naturais, CAV/UDESC. E-mail: a2ftb@cav.udesc.br

(5) Discente de Agronomia, CAV/UDESC. Bolsista de Iniciação Científica/CNPq. E-mail: gabrieloselame@hotmail.com
} 
chuva simulada realizada em solo cultivado com aveia, cujos dados do modelo exponencial $\mathrm{y}=\mathrm{y}_{0}+\mathrm{ae}^{-\mathrm{bx}}$ ajustou-se significativamente; o modelo não se adaptou aos dados da dose zero de dejeto em relação ao $\mathrm{K}$.

Termos de indexação: perdas de água e solo, perdas de fósforo e potássio, suinocultura.

\title{
SUMMARY: INFLUENCE OF SINGLE APPLICATION PIG SLURRY ON WATER EROSION IN A TYPICAL ALFISOL UNDER NO TILLAGE
}

\begin{abstract}
Pig production in the State of Santa Catarina, Brazil, is responsible for many jobs in the rural area and it has great social and economic importance. This study was carried out from March to September 2012 to evaluate the influence of a single application of pig slurry to an Ultisol (Nitossolo Bruno aluminoférrico húmico) soil on losses of water, soil, P and Kdue to water erosion. Treatments consisted of application rates of 0 (zero), 50, 100, and $200 \mathrm{~m}^{3} \mathrm{ha}^{-1}$ applied on the soil surface in a single application, which occurred 30 days after black oat germination. The plots were $11 \times 3.5 \mathrm{~m}$ with a mean slope of $0.14 \mathrm{~m} \mathrm{~m}^{-1}$. During the oat crop cycle, four simulated rainfall tests were carried out, each one with four rainfalls with planned intensity of $65 \mathrm{~mm} \mathrm{~h}^{-1}$ and duration of $75 \mathrm{~min}$, using a Swanson type rainfall simulator. The total soil and water losses by water erosion are not influenced by the pig slurry rates applied on the soil cultivated with black oat. However, there was an influence from the moisture content in the soil before the application of simulated rainfall. The soluble Pand K contents in the runoff water decrease after the application of pig slurry on the soil cultivated with oat for a certain period. When the crop is subjected to simulated rain, the contents decrease from the rain of test 1 to the rain of test 3 , and increase in the rain of test 4 . The soluble $P$ and $K$ contents in the runoff water decrease from the pig slurry application rate of $100 \mathrm{~m}^{3} \mathrm{ha}^{-1}$ to the control treatment (with no pig slurry application) in the simulated rainfall tests 1 and 2. The total losses of soluble $P$ and $K$ in the runoff water are not influenced by the pig slurry rates applied on the soil in cultivation of oat; however, they decrease from the rain of test 1 to test 3 and increase in test 4. The soluble P and K contents in the runoff water decrease with the increased number of simulated rainfall tests in soil cultivated with oat. The data fit the exponential model $y=y_{0}+a^{e-b x}$; except for the data on Kresults with no pig slurry application (rate of zero $\mathrm{m}^{3} \mathrm{ha}^{-1}$ ).
\end{abstract}

Index terms: water and soil losses, phosphorus and potassium losses, pig production.

\section{INTRODUÇÃO}

A produção de suínos no Estado de Santa Catarina está concentrada principalmente nas regiões oeste, meio-oeste e sul, sob confinamento total em todas as etapas da produção. Esse sistema criatório concentra os dejetos nessas regiões, quase sempre na forma líquida, que são utilizados como fertilizantes nas lavouras, na própria propriedade ou nas vizinhanças, a fim de evitar o transporte a grandes distâncias em razão do alto custo. Esse procedimento tem resultado na aplicação desse dejeto nas lavouras, na superfície do solo, em quantidades maiores do que as recomendadas por Corrêa et al. (2011).

Os efeitos benéficos sobre as propriedades físicas do solo, oriundos da aplicação de dejeto de animais, são, em geral, a redução da densidade e o aumento da macroporosidade e da estabilidade dos agregados, principalmente por causa do aumento do teor de matéria orgânica e da atividade biológica no solo (Barilli, 2005; Corrêa et al., 2011). Isso resulta em melhoria dos atributos físicos do solo, com aumento da infiltração de água e aeração do solo, conforme constatado por Andreola et al. (2000), os quais trabalharam com aplicação de dejeto de aves em sistema de semeadura direta por cinco anos.
Bertol (2005) conduziu trabalho com dejeto líquido de suínos aplicado na superfície do solo sob semeadura direta, cujos tratamentos foram submetidos à chuva simulada com microssimulador. Esse autor observou que a enxurrada iniciou mais cedo nos tratamentos com dejeto, em razão do efeito hidrofóbico proporcionado por ele, resultando em maiores perdas de água por erosão hídrica. Esse fenômeno foi observado também por Mori (2009), em experimento com uso de dejeto líquido de bovinos. Bertol et al. (2007c) relataram que a aplicação de dejeto líquido de suínos sobre a superficie do solo em semeadura direta, sob chuva simulada, aumentou as perdas de solo e água por erosão hídrica, carreando nutrientes com potencial para causar eutrofização da água.

As perdas de nutrientes na enxurrada de erosão hídrica são influenciadas por vários fatores; entre eles, a intensidade da chuva, a sequência de chuvas e o intervalo de tempo entre o momento de aplicação do adubo e o da incidência da chuva. As perdas de nutrientes por meio da enxurrada na erosão hídrica são favorecidas pela aplicação de dejeto de animais na superfície do solo, comparadas à sua incorporação, em razão da interação que ocorre entre os nutrientes e a água da chuva (Pierson et al., 2001). Sharpley et al. (2001) verificaram redução nas perdas de fósforo (P) 
por meio da enxurrada de erosão hídrica com o aumento do intervalo de tempo entre a aplicação do adubo e a ocorrência da primeira chuva, principalmente no caso da aplicação de adubo orgânico. A concentração de nutrientes na enxurrada de erosão hídrica varia ainda dentro de uma mesma chuva, que tende a ser maior nos minutos iniciais de chuva (Cassol et al., 2002). Badelucci (1997) verificou que houve significativa redução da concentração de $\mathrm{P}$ ao longo da duração de enxurrada avaliada por erosão hídrica sob chuva simulada. Quanto ao potássio (K), esse autor observou grande variação nos teores por causa das variações na concentração do elemento no solo.

O objetivo deste trabalho foi quantificar as perdas de água e solo e de $\mathrm{P}$ e $\mathrm{K}$ solúveis na água da enxurrada de erosão hídrica, sob a aplicação de uma única dose de dejeto líquido de suínos sobre o solo em sistema de semeadura direta, por meio de chuva simulada.

\section{MATERIAL E MÉTODOS}

A pesquisa foi realizada no Centro de Educação Profissionalizante (CEDUP) do Colégio Agrícola Caetano Costa, em São José do Cerrito, SC, na região do Planalto Sul catarinense, entre março e setembro de 2012. As coordenadas do local são de $27^{\circ} 43$, latitude sul, e $50^{\circ} 31^{\prime}$, longitude oeste de Greenwich, com altitude de $800 \mathrm{~m}$; o clima é do tipo Cfb (subtropical úmido, chuvoso e com verões frescos), segundo a classificação de Köppen; e o relevo do local é ondulado a fortemente ondulado. $\mathrm{O}$ solo é um Nitossolo Bruno aluminoférrico húmico (Embrapa, 2006), de classe textural muito argilosa, cuja composição granulométrica na camada de 0,00-0,05 m de solo é de $62 \%$ de argila, $10 \%$ de silte e $28 \%$ de areia, com teor de carbono orgânico de $25 \mathrm{~g} \mathrm{~kg}^{-1}$, determinada por Barbosa et al. (2012).

Antes de instalar o experimento, foi realizada uma coleta de amostras do solo para caracterizações químicas e físicas, cujos resultados são apresentados no quadro 1.

$\mathrm{O}$ arranjo experimental constituiu-se em dois blocos, com os tratamentos em duas repetições distribuídas inteiramente ao acaso em cada bloco, totalizando oito unidades experimentais. Os tratamentos constituíram-se das seguintes doses de dejeto líquido de suínos: 0, 50, 100 e $200 \mathrm{~m}^{3} \mathrm{ha}^{-1}$. O dejeto continha $2,7 \%$ de matéria seca, e os teores de P extraível e K trocável eram de 5,7 e 4,3 mg kg-1, respectivamente. $\mathrm{O}$ dejeto foi aplicado uma única vez sobre o solo que estava sendo cultivado com aveiapreta, 30 dias após a germinação. No dia subsequente à aplicação do dejeto, foram aplicadas as chuvas simuladas do teste 1 , perfazendo assim um intervalo de tempo de uma tarde e uma noite entre a aplicação do dejeto e a realização desse teste.
Os tratamentos foram aplicados sobre as mesmas parcelas que haviam sido usadas para um trabalho de chuva simulada conduzido anteriormente por Barbosa et al. (2012), com os cultivos de milho, trigo e soja sob semeadura direta, consecutivamente. Os tratamentos avaliados por esses autores eram constituídos de semeadura na direção da pendente e em contorno ao declive, sob dose inteira e meia dose dos resíduos de cada cultura estudada, conforme apresentado no quadro 2. Isso resultou num diferenciado efeito residual do manejo do solo sobre a magnitude de erosão ocorrida em cada uma das parcelas (repetição) neste trabalho.

Para a realização das chuvas simuladas, utilizouse um aparelho simulador de chuva de braços rotativos (Swanson, 1965), tendo sido aplicadas chuvas com duração de 75 min e intensidade constante planejada de $65 \mathrm{~mm} \mathrm{~h}^{-1}$, permitindo, assim, obter a taxa constante de enxurrada. A intensidade e o total de chuva simulada aplicada constam no quadro 3 . Foram realizados quatro testes de chuva simulada, cada teste aplicado num mesmo dia e constituído de quatro chuvas, nas seguintes datas: teste 1 , em 5 de maio de 2012 (30 dias após a germinação da aveia e no dia seguinte ao de aplicação do dejeto); teste 2 , em 26 de maio de 2012; teste 3, em 20 de julho de 2012; e teste 4, em 25 de agosto de 2012. Assim, os intervalos de tempo entre os testes de chuva foram: entre os testes $1 \mathrm{e}$ 2, de 21 dias; entre os testes 2 e 3 , de 54 dias; e entre os testes 3 e 4, de 34 dias. Entre os testes 1 e 2, precipitaram $23 \mathrm{~mm}$ de chuva natural; entre os 2 e $3,215 \mathrm{~mm}$; e entre os 3 e 4, $111 \mathrm{~mm}$ de chuva (INMET, 2012).

Antes do início das chuvas em cada teste, foram coletadas amostras de solo nas profundidades de 0,0-0,1 m e 0,1-0,2 m, em um ponto em cada parcela, com auxílio de um trado, para determinação do teor de água no solo, seguindo método descrito em Embrapa (1997). Com o início da enxurrada decorrente da aplicação das chuvas simuladas, anotou-se e procedeu-se à medição da taxa instantânea de enxurrada, que era feita em intervalos de 5 min até o final dos 75 min de duração da chuva. A cada 5 min, colocou-se sob o fluxo um pote plástico com capacidade de $700 \mathrm{~mL}$, durante o tempo necessário para enchêlo, objetivando coletar enxurrada para nela determinar as perdas de água e solo. Nesse mesmo instante, coletou-se a enxurrada em outro pote plástico com capacidade de $250 \mathrm{~mL}$, da mesma forma, para determinação dos teores e perdas totais de $\mathrm{P}$ e $\mathrm{K}$ na água da enxurrada. As amostras de enxurrada contendo água e sedimentos para análise química foram passadas em filtro contendo membrana de éster de celulose de 0,45 $\mu \mathrm{m}$, obtendo assim a água da enxurrada. Para obter os teores de $\mathrm{P}$ solúvel na água da enxurrada, o método usado foi de Murphy \& Riley (1962); a leitura foi realizada por espectrofotômetro de ultravioleta por meio de fotocolorimetria. Para conseguir os teores de $\mathrm{K}$ solúvel, utilizou-se o método descrito em Tedesco et al. (1995), sendo realizada a leitura no espectrofotômetro de chama. 
Durante a realização de cada uma das chuvas simuladas, foram coletadas amostras também da água do rio em potes plásticos para posterior análise; o tratamento e as determinações realizadas nessa amostra foram as mesmas realizadas nas amostras de água da enxurrada, mencionadas anteriormente.

As amostras de enxurrada para determinar as perdas de solo e água foram pesadas e, posteriormente, secas em estufa, à temperatura de $60{ }^{\circ} \mathrm{C}$ para quantificação da massa de sedimentos. A massa de sedimentos na enxurrada multiplicada pela quantidade de água presente nela antes da secagem resultou na perda total de solo. Os cálculos de perdas de água e solo foram realizados utilizando um programa computacional, do tipo planilha Excel, elaborado pelo Prof. Elemar Antonino Cassol do DS-FA-UFRGS, denominado "Poderosão", por meio da inserção das informações: intensidade e duração da chuva,

Quadro 1. Valores de porosidade total (Pt), microporosidade (Mi), macroporosidade (Ma), densidade do solo (Ds), diâmetro médio ponderado de agregados (DMP) e teores de fósforo disponível e potássio trocável, em quatro camadas do solo de cada uma das parcelas (repetições - R), onde mais tarde foram instalados os tratamentos referentes às doses (D) do dejeto líquido de suínos

\begin{tabular}{|c|c|c|c|c|c|c|c|}
\hline Repetição/Tratamento & $\mathbf{P t}$ & Mi & Ma & Ds & DMP & $\mathbf{P}$ & $\mathbf{K}$ \\
\hline & . & $-\%$ & 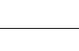 & $\mathrm{kg} \mathrm{dm}{ }^{-3}$ & $\mathrm{~mm}$ & 1 & 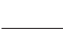 \\
\hline & & & & $0,00-0,025 \mathrm{~m}$ & & & \\
\hline R1 (D200) & 61,5 & 42,4 & 19,1 & 1,06 & 5,81 & 11,28 & 50 \\
\hline R2 (D200) & 56,6 & 28,0 & 28,7 & 1,21 & 5,39 & 12,03 & 116 \\
\hline R1 (D100) & 44,7 & 27,2 & 17,5 & 1,54 & 5,12 & 14,34 & 374 \\
\hline $\mathrm{R} 2(\mathrm{D} 100)$ & 51,9 & 28,5 & 23,4 & 1,34 & 5,41 & 10,80 & 231 \\
\hline R1 (D50) & 61,0 & 29,5 & 31,4 & 1,07 & 5,95 & 9,21 & 55 \\
\hline R2 (D50) & 55,8 & 27,9 & 27,9 & 1,23 & 4,85 & 18,21 & 50 \\
\hline R1 (D0) & 55,8 & 32,3 & 23,5 & 1,23 & 5,54 & 22,92 & 72 \\
\hline \multirow[t]{2}{*}{ R2 (D0) } & 48,3 & 27,4 & 20,9 & 1,44 & 5,19 & 7,08 & 374 \\
\hline & \multicolumn{7}{|c|}{$0,025-0,075 \mathrm{~m}$} \\
\hline R1 (D200) & 53,0 & 29,3 & 23,6 & 1,31 & 5,89 & 4,92 & 50 \\
\hline R2 (D200) & 48,3 & 27,7 & 20,7 & 1,44 & 5,51 & 6,24 & 49 \\
\hline R1 (D100) & 47,6 & 27,6 & 20,0 & 1,46 & 5,31 & 4,02 & 303 \\
\hline R2 (D100) & 48,8 & 29,6 & 19,2 & 1,43 & 5,67 & 6,21 & 33 \\
\hline R1 (D50) & 51,0 & 31,9 & 19,1 & 1,37 & 5,43 & 4,98 & 270 \\
\hline R2 (D50) & 45,3 & 27,9 & 17,4 & 1,52 & 5,21 & 4,92 & 50 \\
\hline R1 (D0) & 51,9 & 31,9 & 20,0 & 1,34 & 5,26 & 8,45 & 17 \\
\hline \multirow[t]{2}{*}{ R2 (D0) } & 52,3 & 39,7 & 12,6 & 1,33 & 5,37 & 5,52 & 50 \\
\hline & \multicolumn{7}{|c|}{$0,075-0,125 \mathrm{~m}$} \\
\hline R1 (D200) & 50,2 & 30,1 & 20,0 & 1,39 & 4,98 & 5,13 & 121 \\
\hline R2 (D200) & 48,0 & 28,6 & 19,4 & 1,45 & 6,06 & 3,03 & 132 \\
\hline R1 (D100) & 45,1 & 28,1 & 17,0 & 1,53 & 5,91 & 2,67 & 35 \\
\hline R2 (D100) & 49,0 & 28,7 & 20,2 & 1,42 & 5,22 & 2,58 & 77 \\
\hline R1 (D50) & 51,1 & 30,3 & 20,9 & 1,36 & 5,61 & 3,18 & 193 \\
\hline R2 (D50) & 46,6 & 29,2 & 17,4 & 1,49 & 5,80 & 3,81 & 27 \\
\hline R1 (D0) & 49,3 & 29,1 & 20,2 & 1,41 & 5,66 & 4,81 & 160 \\
\hline \multirow[t]{2}{*}{ R2 (D0) } & 48,0 & 29,3 & 18,8 & 1,45 & 5,50 & 2,10 & 35 \\
\hline & \multicolumn{7}{|c|}{$0,125-0,20 \mathrm{~m}$} \\
\hline R1 (D200) & 52,5 & 32,1 & 20,4 & 1,32 & 4,07 & 0,63 & 19 \\
\hline R2 (D200) & 50,2 & 31,4 & 18,9 & 1,39 & 5,29 & 1,59 & 94 \\
\hline R1 (D100) & 48,2 & 30,2 & 18,0 & 1,44 & 5,03 & 2,55 & 132 \\
\hline R2 (D100) & 51,9 & 34,2 & 17,8 & 1,34 & 5,05 & 1,26 & 49 \\
\hline R1 (D50) & 47,1 & 27,4 & 19,7 & 1,47 & 3,35 & 0,96 & 171 \\
\hline R2 (D50) & 52,8 & 33,4 & 19,4 & 1,31 & 4,58 & 1,35 & 22 \\
\hline R1 (D0) & 48,5 & 30,0 & 18,5 & 1,43 & 3,58 & 1,20 & 38 \\
\hline R2 (D0) & 50,0 & 31,6 & 18,4 & 1,39 & 4,52 & 0,66 & 83 \\
\hline
\end{tabular}


declividade média do terreno nas parcelas, massa de sedimentos e taxa de enxurrada. Assim, obtiveramse as perdas de solo e água instantâneas e totais.

Quadro 2. Direção de semeadura e massa seca de resíduos culturais na superfície do solo, em cada uma das parcelas (repetições - R), onde mais tarde foram instalados os tratamentos referentes às doses $(\mathrm{D})$ do dejeto líquido de suínos

\begin{tabular}{|c|c|c|}
\hline $\begin{array}{l}\text { Repetição/ } \\
\text { Tratamento }\end{array}$ & $\begin{array}{l}\text { Direção de } \\
\text { semeadura }\end{array}$ & $\begin{array}{c}\text { Massa de } \\
\text { resíduo }\end{array}$ \\
\hline & & $\mathrm{tha}^{-1}$ \\
\hline & Milho (2009) & \\
\hline R1 (D200) & Contorno & $4,8-\mathrm{Md}$ \\
\hline R2 (D200) & Morro abaixo & 4,8 - Md \\
\hline R1 (D100) & Contorno & 9,6 - Di \\
\hline R2 (D100) & Contorno & $4,8-\mathrm{Md}$ \\
\hline R1 (D50) & Morro abaixo & 9,6 - Di \\
\hline R2 (D50) & Morro abaixo & $4,8-\mathrm{Md}$ \\
\hline R1 (D0) & Morro abaixo & 9,6 - Di \\
\hline \multirow[t]{2}{*}{ R2 (D0) } & Contorno & 9,6 - Di \\
\hline & Trigo (2010) & \\
\hline R1 (D200) & Contorno & $1,8-\mathrm{Md}$ \\
\hline R2 (D200) & Morro abaixo & $1,8-\mathrm{Md}$ \\
\hline R1 (D100) & Contorno & 3,6 - Di \\
\hline R2 (D100) & Contorno & $1,8-\mathrm{Md}$ \\
\hline R1 (D50) & Morro abaixo & 3,6 - Di \\
\hline R2 (D50) & Morro abaixo & $1,8-\mathrm{Md}$ \\
\hline R1 (D0) & Morro abaixo & 3,6 - Di \\
\hline \multirow[t]{2}{*}{ R2 (D0) } & Contorno & 3,6 - Di \\
\hline & Soja (2010) & \\
\hline R1 (D200) & Contorno & $1,8-\mathrm{Md}$ \\
\hline R2 (D200) & Morro abaixo & $1,8-\mathrm{Md}$ \\
\hline R1 (D100) & Contorno & 3,6 - Di \\
\hline R2 (D100) & Contorno & $1,8-\mathrm{Md}$ \\
\hline R1 (D50) & Morro abaixo & 3,6 - Di \\
\hline R2 (D50) & Morro abaixo & 1,8 - Md \\
\hline R1 (D0) & Morro abaixo & 3,6 - Di \\
\hline R2 (D0) & Contorno & 3,6 - Di \\
\hline
\end{tabular}

Fonte: Adaptado de Barbosa (2011). Md: meia dose do resíduo; e Di: dose inteira do resíduo.
Para facilitar a comparação dos resultados, ajustaram-se os dados de perdas totais de água e solo para a intensidade de chuva planejada de $65 \mathrm{~mm} \mathrm{~h}^{-1}$, e as perdas totais de solo foram corrigidas, ainda, para a declividade, padronizando-as para a declividade média das parcelas, seguindo o proposto por Wischmeier \& Smith (1978), conforme a equação a seguir:

$$
\mathrm{S}=0,065+4,56 \operatorname{sen} \theta+65,41(\operatorname{sen} \theta)^{2}
$$

em que $\mathrm{S}=$ fator declividade da EUPS; e $\theta=$ ângulo de declive do terreno.

Com os teores de $\mathrm{P}$ e $\mathrm{K}$ solúvel na água da enxurrada, e com as quantidades de água perdidas por erosão, foram calculadas as perdas instantâneas e totais dos elementos solúveis na água da enxurrada.

Os dados de perdas de água, solo, $\mathrm{P}$ e K e de teores de $\mathrm{P}$ e K solúvel na água da enxurrada foram tratados estatisticamente, usando a análise da variância; quando as diferenças entre os tratamentos foram significativas, foi realizado o teste de Duncan a $5 \%$, utilizando-se o programa estatístico ASSISTAT 7.6 Beta (2012). O modelo exponencial $\mathrm{y}=\mathrm{y}_{0}+\mathrm{ae}$-bx foi ajustado aos valores de teores de $\mathrm{P}$ e $\mathrm{K}$ solúvel na água da enxurrada em relação aos testes de chuva realizados.

\section{RESULTADOS E DISCUSSÃO}

Os valores de teor de água do solo antecedente à realização das chuvas simuladas podem ser considerados altos para esse tipo de solo, apresentando maior variação entre as épocas em que foram realizadas as chuvas de cada teste, com pequenas diferenças entre os tratamentos e as camadas do solo num mesmo teste (Quadro 4), conforme verificado por Costa (2012). Em geral, os valores variaram de 18 a $31 \%$ na camada $0,0-0,1 \mathrm{~m}$ e de 19 a $29 \%$, na de 0,1-0,2 m. Nas chuvas dos três primeiros testes, o teor de água foi em geral maior, com pequena diferença de valores nas duas camadas do solo, em relação às chuvas do teste 4 , em que essa variável foi menor nas duas camadas, em razão, principalmente, à ausência de chuva natural nos dias que antecederam a realização das chuvas desse teste.

Quadro 3. Intensidade (I) e lâmina (L) de chuva simulada aplicada por teste de chuva sobre os tratamentos referentes às doses (D) do dejeto líquido de suínos aplicadas na cultura da aveia-preta

\begin{tabular}{|c|c|c|c|c|c|c|c|c|}
\hline \multirow{2}{*}{ Tratamento } & \multicolumn{2}{|c|}{ Teste 1} & \multicolumn{2}{|c|}{ Teste 2} & \multicolumn{2}{|c|}{ Teste 3} & \multicolumn{2}{|c|}{ Teste 4} \\
\hline & I & $\mathbf{L}$ & I & $\mathbf{L}$ & $\mathbf{I}$ & $\mathbf{L}$ & I & $\mathbf{L}$ \\
\hline & $\mathrm{mm} \mathrm{h}^{-1}$ & $\mathrm{~mm}$ & $\mathrm{~mm} \mathrm{~h}^{-1}$ & $\mathrm{~mm}$ & $\mathrm{~mm} \mathrm{~h}^{-1}$ & $\mathrm{~mm}$ & $\mathrm{~mm} \mathrm{~h}^{-1}$ & $\mathrm{~mm}$ \\
\hline D200 & 63,9 & 79,9 & 60,7 & 75,8 & 71,9 & 89,8 & 62,6 & 78,2 \\
\hline D100 & 60,6 & 75,8 & 62,2 & 77,7 & 70,5 & 88,1 & 62,8 & 78,4 \\
\hline D50 & 60,6 & 75,8 & 62,2 & 77,7 & 70,5 & 88,1 & 62,8 & 78,4 \\
\hline D0 & 63,9 & 79,9 & 60,7 & 75,8 & 71,9 & 89,8 & 62,6 & 78,2 \\
\hline
\end{tabular}


Quadro 4. Teor de água antecedente às chuvas simuladas, em duas camadas do solo e tempo de início do escoamento superficial (Ti), em razão dos tratamentos (D) de doses de dejeto líquido de suínos aplicadas por teste de chuva simulada (média das repetições)

\begin{tabular}{lccc}
\hline Tratamento & $\mathbf{0 , 0 - 0 , 1} \mathbf{~ m}$ & $\mathbf{0 , 1 - 0 , 2} \mathbf{~ m}$ & Ti \\
\cline { 2 - 3 } & & min \\
\cline { 2 - 3 } D200 & & Teste 1 & \\
D100 & 27 & 26 & 11 \\
D50 & 27 & 28 & 21 \\
D0 & 27 & 27 & 32 \\
& 25 & 26 & 28 \\
D200 & & Teste 2 & \\
D100 & 27 & 27 & 33 \\
D50 & 28 & 28 & 30 \\
D0 & 31 & 25 & 36 \\
& 26 & 26 & 28 \\
D200 & & Teste 3 & \\
D100 & 27 & 28 & 13 \\
D50 & 29 & 29 & 17 \\
D0 & 28 & 27 & 21 \\
& 29 & 27 & 17 \\
D200 & & Teste 4 & \\
D100 & 18 & 19 & 46 \\
D50 & 20 & 21 & 61 \\
D0 & 20 & 20 & 71 \\
\hline
\end{tabular}

O tempo de início de enxurrada apresentou valores entre 11 e 71 min (Quadro 4), variando menos entre os tratamentos do que entre as chuvas de um teste a outro. Os tratamentos influenciaram o tempo de início de enxurrada nas chuvas do teste 1 ; no tratamento T200, o valor foi menor, seguido pelo T100, de acordo com Bertol (2005) e Peles (2007). Esses autores trabalharam com dejeto líquido de suínos aplicado na superficie do solo em semeadura direta e, posteriormente, realizaram chuva simulada com microssimulador de chuva. Observou-se que a enxurrada iniciou mais cedo nos tratamentos com aplicação de dejeto em razão, segundo os autores, do efeito hidrofóbico proporcionado por esse dejeto, sendo esse fenômeno também observado por Haynes \& Swift (1990) e Mori et al. (2009), com o uso de dejeto líquido de bovino.

Nas chuvas dos testes 2 e 3 (Quadro 4), a enxurrada variou menos do que naquelas dos outros dois testes, resultando em comportamento variado dos tratamentos sobre o início da enxurrada. Isso ocorreu possivelmente por causa da decomposição do dejeto, que percolou para camadas inferiores do solo com a água das chuvas naturais, precipitadas nos intervalos dos testes da chuva simulada, como relatado por Bertol (2005), bem como pelo transporte superficial de dejeto ocorrido pela água da enxurrada nas chuvas do teste
1. Nas chuvas do teste 4, o tempo de início da enxurrada foi alto em relação às chuvas dos outros testes, em razão do menor teor de água do solo antecedente à aplicação da chuva, causado pela menor precipitação natural no intervalo dos testes 3 e 4 . O teor de água do solo exerceu grande influência sobre o tempo de início de enxurrada, de modo que quanto maior o teor, mais rapidamente diminui a taxa de infiltração.

As perdas de solo variaram 2.050 vezes entre a menor e a maior, com valores entre 0,1 e $205 \mathrm{~kg} \mathrm{ha}^{-1}$ (Quadro 5), dados esses semelhantes aos encontrados por Peles (2007). Esses valores foram considerados baixos para esse tipo de solo em razão de o cultivo ter sido conduzido sob sistema de semeadura direta e, também, por tratar-se de solo relativamente resistente à erosão com erodibilidade de 0,011 t ha h ha ${ }^{-1} \mathrm{MJ}^{-1} \mathrm{~mm}^{-1}$, segundo Bertol et al. (2007b). As perdas tenderam, em geral, a diminuir das chuvas do teste 1 para as do 4, em virtude do aumento da proteção do solo pela cultura, que se desenvolveu ao longo do tempo em que as chuvas foram aplicadas. Contribuiu para isso o fato de o solo mais prontamente disponível ao transporte ter sido efetivamente transportado nas chuvas dos testes iniciais. As maiores perdas de solo ocorreram nas chuvas dos testes 1 e 2; e as menores naquelas dos testes 3 e 4, com exceção da perda ocorrida no tratamento D50, que foi levemente maior nas chuvas do teste 3 do que nas do 2. Assim, ao final do ciclo da aveia, por ocasião da aplicação das chuvas do teste 4 , as perdas de solo foram menores do que das dos demais testes, justificadas, além do pleno desenvolvimento da cultura, pelo baixo teor de água no solo (Quadro 3). Isso permitiu que ocorresse maior infiltração, fazendo com que a enxurrada levasse mais tempo para iniciar e, consequentemente, restando menor espaço de tempo para transporte de sedimentos.

Os dados de perda de solo não diferiram estatisticamente (Quadro 5) por causa da grande variação entre as repetições, em razão do seguinte motivo: a área experimental foi utilizada, por três cultivos anteriores a esse, com milho, trigo e soja, consecutivamente, para outro experimento de quantificação de erosão sob chuva simulada, conforme detalhado em Material e Métodos. Esse efeito residual do manejo anterior do solo refletiu-se nos dados deste experimento. Mesmo sem ter ocorrido diferença estatística, é importante fazer uma abordagem sobre algumas diferenças numéricas nos valores de perda de solo. Assim, no tratamento D0, essas perdas foram 2,7 vezes maiores do que a média dos demais tratamentos, no total das chuvas simuladas de todos os testes. Isso confirma o fato de que o dejeto líquido de suínos, aplicado na superfície do solo, tendeu a reduzir a erosão do solo, como constatado por Dieter (2009) e Peles (2007), independentemente se a dose aplicada foi 50,100 ou $200 \mathrm{~m}^{3} \mathrm{ha}^{-1}$.

As perdas de água pela enxurrada variaram de 1 a $50 \%$ do volume da chuva simulada aplicada, com os 
Quadro 5. Valores de perdas totais de solo e água e de teores e perdas totais de fósforo e potássio solúveis na água da enxurrada, por teste de chuva simulada, em razão dos tratamentos (D) de doses de dejeto líquido de suínos aplicadas (média das repetições)

\begin{tabular}{|c|c|c|c|c|c|}
\hline Tratamento & Teste 1 & Teste 2 & Teste 3 & Teste 4 & Total \\
\hline & \multicolumn{5}{|c|}{ Perda de solo $\left(\mathrm{kg} \mathrm{ha}^{-1}\right)$} \\
\hline D200 & $44 \mathrm{a}$ & $53 \mathrm{a}$ & $39 \mathrm{a}$ & $11 \mathrm{a}$ & $147 \mathrm{a}$ \\
\hline D100 & $147 \mathrm{a}$ & $91 \mathrm{a}$ & $16 \mathrm{a}$ & $4 \mathrm{a}$ & $258 \mathrm{a}$ \\
\hline D50 & $35 \mathrm{a}$ & $46 \mathrm{a}$ & $55 \mathrm{a}$ & $0,1 \mathrm{a}$ & $136 \mathrm{a}$ \\
\hline Do & $119 \mathrm{a}$ & $205 \mathrm{a}$ & $17 \mathrm{a}$ & $22 \mathrm{a}$ & $488 \mathrm{a}$ \\
\hline \multirow[t]{2}{*}{ CV (\%) } & 98 & 94 & 113 & 183 & 105 \\
\hline & \multicolumn{5}{|c|}{ Perda de água (\% da chuva) } \\
\hline D200 & $21 \mathrm{a}$ & $14 \mathrm{~b}$ & $43 \mathrm{a}$ & $3 \mathrm{a}$ & $20 \mathrm{a}$ \\
\hline D100 & $34 \mathrm{a}$ & $31 \mathrm{a}$ & $45 \mathrm{a}$ & $6 \mathrm{a}$ & $29 \mathrm{a}$ \\
\hline D50 & $15 \mathrm{a}$ & $21 \mathrm{ab}$ & $35 \mathrm{a}$ & $1 \mathrm{a}$ & $18 \mathrm{a}$ \\
\hline D0 & $22 \mathrm{a}$ & $33 \mathrm{a}$ & $50 \mathrm{a}$ & $3 \mathrm{a}$ & $27 \mathrm{a}$ \\
\hline \multirow[t]{2}{*}{ CV (\%) } & 31 & 15 & 24 & 84 & 75 \\
\hline & \multicolumn{5}{|c|}{ Teor de $\mathrm{P}\left(\mathrm{mg} \mathrm{L}^{-1}\right)$} \\
\hline D200 & $1,42 \mathrm{a}$ & $0,79 \mathrm{a}$ & $0,21 \mathrm{a}$ & $0,57 \mathrm{a}$ & $0,65^{(1)} \mathrm{a}$ \\
\hline D100 & $1,21 \mathrm{a}$ & $0,77 \mathrm{a}$ & $0,20 \mathrm{a}$ & $0,51 \mathrm{a}$ & $0,67^{(1)} \mathrm{a}$ \\
\hline D50 & $1,01 \mathrm{a}$ & $0,74 \mathrm{a}$ & $0,23 \mathrm{a}$ & $0,69 \mathrm{a}$ & $0,67^{(1)} \mathrm{a}$ \\
\hline D0 & $0,63 \mathrm{a}$ & $0,51 \mathrm{a}$ & $0,23 \mathrm{a}$ & $0,44 \mathrm{a}$ & $0,45^{(1)} \mathrm{a}$ \\
\hline \multirow[t]{2}{*}{ CV (\%) } & 28 & 29 & 35 & 36 & 19 \\
\hline & \multicolumn{5}{|c|}{ Teor de $K\left(\mathrm{mg} \mathrm{L}^{-1}\right)$} \\
\hline D200 & $10,22 \mathrm{a}$ & $5,47 \mathrm{a}$ & $2,25 \mathrm{a}$ & $6,47 \mathrm{a}$ & $5,43^{(1)} \mathrm{a}$ \\
\hline D100 & $10,28 \mathrm{a}$ & $7,96 \mathrm{a}$ & $2,53 \mathrm{a}$ & $6,39 \mathrm{a}$ & $8,29^{(1)} \mathrm{a}$ \\
\hline D50 & $10,23 \mathrm{a}$ & $5,04 \mathrm{a}$ & $2,22 \mathrm{a}$ & $6,14 \mathrm{a}$ & $5,91^{(1)} \mathrm{a}$ \\
\hline Do & $5,55 \mathrm{a}$ & $4,89 \mathrm{a}$ & $2,57 \mathrm{a}$ & $6,09 \mathrm{a}$ & $5,53^{(1)} \mathrm{a}$ \\
\hline \multirow[t]{2}{*}{ CV (\%) } & 29 & 45 & 36 & 37 & 11 \\
\hline & \multicolumn{5}{|c|}{ Perda de $\mathrm{P}\left(\mathrm{g} \mathrm{ha}^{-1}\right)$} \\
\hline D200 & $247 \mathrm{a}$ & $78 \mathrm{a}$ & $81 \mathrm{a}$ & $14 \mathrm{a}$ & $420 \mathrm{ab}$ \\
\hline D100 & $354 \mathrm{a}$ & $186 \mathrm{a}$ & $70 \mathrm{a}$ & $23 \mathrm{a}$ & $634 \mathrm{a}$ \\
\hline D50 & $125 \mathrm{a}$ & $117 \mathrm{a}$ & $71 \mathrm{a}$ & $2 \mathrm{a}$ & $315 \mathrm{~b}$ \\
\hline D0 & $106 \mathrm{a}$ & $127 \mathrm{a}$ & $107 \mathrm{a}$ & $10 \mathrm{a}$ & $350 \mathrm{~b}$ \\
\hline \multirow[t]{2}{*}{ CV (\%) } & 39 & 37 & 56 & 98 & 21 \\
\hline & \multicolumn{5}{|c|}{ Perda de $K\left(\mathrm{~g} \mathrm{ha}^{-1}\right)$} \\
\hline D200 & $1.795 \mathrm{a}$ & $555 \mathrm{a}$ & $857 \mathrm{a}$ & $77 \mathrm{a}$ & $3.285 \mathrm{a}$ \\
\hline D100 & $2.912 \mathrm{a}$ & $1.948 \mathrm{a}$ & $1.086 \mathrm{a}$ & $322 \mathrm{a}$ & $6.268 \mathrm{a}$ \\
\hline D50 & $1.325 \mathrm{a}$ & $755 \mathrm{a}$ & $684 \mathrm{a}$ & $8 \mathrm{a}$ & $2.763 \mathrm{a}$ \\
\hline D0 & $1.145 \mathrm{a}$ & $1.225 \mathrm{a}$ & $1.230 \mathrm{a}$ & $118 \mathrm{a}$ & $3.718 \mathrm{a}$ \\
\hline CV (\%) & 36 & 60 & 48 & 152 & 31 \\
\hline
\end{tabular}

Médias seguidas pela mesma letra na coluna não diferem estatisticamente entre si pelo teste de Duncan a 5 \%. ${ }^{(1)}$ Média dos testes.

maiores valores observados nas chuvas do teste 3 e os menores nas do 4 (Quadro 5), de acordo com a variação ocorrida na altura total de chuva aplicada (Quadro 3), principalmente, e com a variação no teor de água no solo antecedente às chuvas (Quadro 4). Assim, podese considerar que essas perdas foram altas nas chuvas do teste 3 , entre 35 e $50 \%$ da chuva aplicada e foram baixas nas do teste 4 , entre 1 e $6 \%$. Entre os tratamentos, as perdas de água não diferiram estatisticamente, com exceção daquelas ocorridas nas chuvas do teste 2 , em que os tratamentos D100 e D0 apresentaram perdas maiores. Assim, de maneira geral, as doses do dejeto líquido de suínos aplicadas não influenciaram as perdas de água. Isso concorda com Dal Bosco (2008), que aplicou doses crescentes, até $200 \mathrm{~m}^{3} \mathrm{ha}^{-1} \mathrm{ano}^{-1}$, de dejeto líquido de suínos, em solo de textura argilosa sob semeadura direta, e submeteu à chuva simulada. No entanto, Silveira (2009), trabalhando com dejeto líquido de bovinos, em doses crescentes, até $180 \mathrm{~m}^{3} \mathrm{ha}^{-1} \mathrm{ano}^{-1}$, em solo de 
textura arenosa sob semeadura direta, observou maiores perdas de água no tratamento com a menor dose do dejeto, o que também foi constatado por Mori et al. (2009) em experimento de mesma natureza. Peles (2007), em experimento sobre solo de textura argilosa manejado sob semeadura direta e submetido à chuva simulada, observou que as maiores perdas de água por enxurrada ocorreram nos tratamentos com as maiores doses de dejeto líquido de suínos. Bertol (2005) constatou que o dejeto líquido de suínos aplicado sobre um solo de textura argilosa, e submetido à chuva simulada, proporcionou as maiores perdas de água nos tratamentos em que houve aplicação do dejeto, em comparação com a testemunha sem dejeto.

Em geral, as perdas de água pela enxurrada são mais influenciadas pelo tipo de solo e seus atributos físicos e pela cobertura superficial, do que propriamente pelas doses do dejeto aplicado ao solo. A dose do dejeto que influenciou o tempo de inicio da enxurrada (Quadro 4) não interferiu as perdas de água (Quadro 5), apesar de a enxurrada ter iniciado antes nos tratamentos de maior dose. Em parte, isso é justificado pela atuação da cobertura do solo por resíduos culturais, que dificultou o contato direto do dejeto com o solo e, assim, possivelmente, diminuiu a obstrução dos seus poros. Em vista dos dados aqui discutidos e confrontados com os da literatura, percebeu-se que as perdas de água por enxurrada se comportaram-se de modo variável de acordo com a dose do dejeto líquido de suínos aplicado ao solo.

Os teores de $\mathrm{P}$ e K solúveis na água da enxurrada não variaram estatisticamente entre tratamentos, nem nas chuvas de cada teste, individualmente, nem na média das chuvas de todos os testes (Quadro 5). Isso ocorreu, principalmente, em razão da grande variação de valores entre as repetições, justificada pelo histórico de manejo do solo nas parcelas onde se instalaram os diversos tratamentos (Material e Métodos). No entanto, alguns comentários podem ser feitos com base nas tendências apresentadas pelos teores desse elemento. Para o P, especialmente nas chuvas do teste 1 , houve clara tendência de diminuição dos teores do elemento na água da enxurrada do tratamento D200 para o D0, com menor clareza dessa tendência nas chuvas do teste 2 e sem nenhuma tendência nas dos testes 3 e 4 . Isso evidenciou que, pelos menos em termos de tendência, a dose de dejeto líquido de suínos influenciou o aumento do teor de $\mathrm{P}$ na água da enxurrada, no caso de uma chuva realizada imediatamente após a aplicação do dejeto na superfície do solo, conforme verificado por Bertol (2005). Para o K, os valores foram iguais numericamente nos tratamentos D200, D100 e D50 e claramente inferiores no D0, nas chuvas do teste 1 , sem nenhuma tendência nas dos testes 2 e 3 e com fraca tendência de diminuição do tratamento D200 para o D0, nas chuvas do teste 4. Portanto, para o K, qualquer das doses do dejeto aplicadas ao solo teve $\mathrm{o}$ mesmo efeito no teor do elemento na enxurrada, independentemente do momento de aplicação da chuva, diferindo apenas em relação à condição em que não se aplicou dejeto ao solo. E preciso considerar, ainda, que a condição experimental foi particular em relação ao que pode acontecer em geral no campo, pois se aplicou a chuva simulada poucas horas após a aplicação do dejeto ao solo.

Os teores de $\mathrm{P}$ e K na água da enxurrada coletada nas chuvas do teste 4 aumentaram em relação aos verificados nas do teste 3 , independentemente da dose de dejeto, atingindo, em geral, valores semelhantes aos observados nas chuvas do teste 3 (Quadro 5). Isso é explicado pelo efeito da decomposição de resíduos vegetais existentes na superfície do solo e pela mineralização da matéria orgânica decorrente disso, para os dois elementos; para o K, também pela lixiviação do elemento da parte aérea das plantas de aveia na fase final do ciclo. Como a erosão hídrica é um fenômeno de superfície do solo, os elementos químicos ali disponíveis são facilmente transportados pela água de enxurrada.

As perdas totais de $\mathrm{P}$ solúvel na água de enxurrada variaram de 2 a $354 \mathrm{~g} \mathrm{ha}^{-1}$, considerando as chuvas de todos os testes e tratamentos (Quadro 5). Esses valores são semelhantes aos encontrados por Peles (2007), em trabalho sob aplicação de dejeto líquido de suínos. As maiores perdas de $\mathrm{P}$ ocorreram nas chuvas do teste 1; e, as menores, nas do teste 4, com redução de $94 \%$, na média dos tratamentos. A maior diminuição ocorreu no tratamento D50 e a menor, no D0. A redução nos valores de perdas de $\mathrm{P}$ na água da enxurrada nas chuvas do teste 1 para as do teste 4 foi normal, de acordo com a diminuição dos valores de teor do elemento na água, conforme dados obtidos também por outros autores (Bertol et al., 2007a; Gebler et al., 2012a) e com a diminuição dos valores de perdas de água.

No tratamento D50, as perdas totais de P na água da enxurrada foram $40 \%$ menores do que na média dos tratamentos D200, D100 e D0, no total das chuvas dos quatro testes (Quadro 5). Assim, os dados evidenciaram clara tendência de diminuição dessas perdas com a redução da dose do dejeto aplicada ao solo, de acordo com outros trabalhos (Bertol, 2005; Bertol et al., 2007c). No entanto, as maiores perdas de $\mathrm{P}$, em termos numéricos e no total das chuvas dos quatro testes, ocorreram no tratamento D100, determinada principalmente pelas maiores perdas de água ocorridas nesse tratamento em relação aos demais. Considerando as chuvas dos testes, individualmente, em nenhum deles houve diferença estatística entre os tratamentos, apesar da grande diferença numérica nos valores, em razão da grande variação entre as repetições, denotada pelos altos valores de coeficiente de variação. As quantidades de $P$ perdido podem ser consideradas baixas do ponto de vista agronômico e econômico, em face da quantidade aplicada ao solo; entretanto, muito altas, tratando-se do ponto de vista ambiental, por causa do grande potencial poluidor de águas que apresenta esse elemento, segundo Gebler et al. (2012b). 

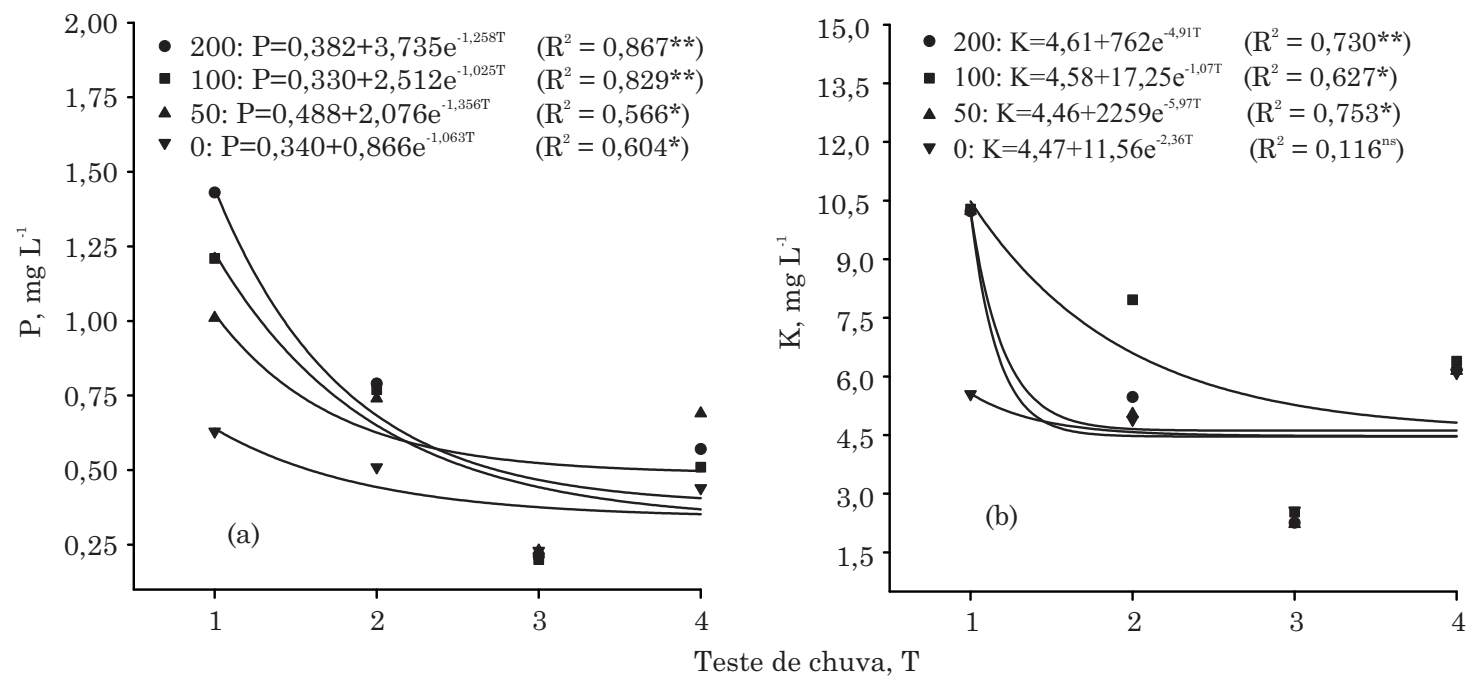

Figura 1. Relação entre os teores de fósforo (a) e potássio (b) solúvel obtidos na água da enxurrada ao final da chuva e o número de teste de chuva simulada aplicada, em cada um dos tratamentos de dose de dejeto líquido de suínos (média das repetições).

As perdas totais de $\mathrm{K}$ solúvel na água da enxurrada variaram entre 8 e $2.912 \mathrm{~g} \mathrm{ha}^{-1}$, entre as chuvas de todos os testes e tratamentos (Quadro 5). Esses valores são semelhantes aos encontrados por Peles (2007), com aplicação de dejeto líquido de suínos, e por Mori et al. (2009), com aplicação de dejeto líquido de bovinos. Do mesmo modo como para o $\mathrm{P}$, as maiores perdas de $\mathrm{K}$ ocorreram nas chuvas do teste $1 \mathrm{e}$, as menores, nas do teste 4, com redução de $93 \%$, na média dos tratamentos. A maior redução na perda de K ocorreu no tratamento D50 e a menor, no D100. A diminuição nos valores de perdas de $\mathrm{K}$ na água da enxurrada das chuvas do teste 1 para as do teste 4 foi normal, de acordo com a redução dos valores de teor do elemento na água, exceto para o tratamento D0, conforme dados obtidos por outros autores (Bertol et al., 2007c) e com a diminuição dos valores de perdas de água.

No tratamento D50, as perdas totais de K na água da enxurrada foram $42 \%$ menores do que na média dos tratamentos D200 e D100, em termos numéricos e sem diferença estatística, no total das chuvas dos quatro testes (Quadro 5). Assim, os dados apresentaram tendência de diminuição dessas perdas com a diminuição da dose do dejeto aplicado ao solo, de acordo com outros trabalhos (Peles, 2007; Mori et al., 2009). No entanto, do mesmo modo como para o $\mathrm{P}$, as maiores perdas de $\mathrm{K}$, em termos numéricos e no total das chuvas dos quatro testes, ocorreram no tratamento T100, determinadas tanto pelas maiores perdas de água quanto pelos maiores teores do elemento na água da enxurrada, ocorridos nesse tratamento em relação aos demais. Considerando as chuvas dos testes, individualmente, em nenhum deles houve diferença estatística entre os tratamentos, em concordância parcial com os valores de perdas de água e de teores do elemento na água da enxurrada. As quantidades de $\mathrm{K}$ perdidas podem ser consideradas baixas do ponto de vista agronômico e econômico, em face da quantidade aplicada ao solo; porém, merecem atenção, em razão de a perda de K estar relacionada com o empobrecimento do solo (Schick et al., 2000). As quantidades perdidas desse elemento são semelhantes aos valores encontrados por Peles (2007), com aplicação de dejeto líquido de suínos, e por Mori et al. (2009), com aplicação de dejeto líquido de bovinos.

Os teores de $\mathrm{P}$ e $\mathrm{K}$ solúvel na água da enxurrada diminuíram com o aumento do número de teste de chuva simulada realizada, independentemente da dose de dejeto líquido de suínos aplicada sobre o solo (Figura 1). O modelo exponencial do tipo $y=y_{0}+a e^{-b x}$ ajustouse significativamente aos dados para todos os tratamentos em relação ao $\mathrm{P}$ e para os tratamentos sob aplicação do dejeto em relação ao K. A maior taxa de redução ocorreu entre as chuvas do teste 1 e as do teste 2, tendendo a estabilizar os teores dos elementos na água da enxurrada a partir daí. Isso confirmou que a ocorrência de chuva imediatamente após a aplicação do dejeto no solo caracterizou o momento mais crítico em termos de perdas desses elementos pela água de enxurrada da erosão hídrica, conforme verificado por Bertol et al. (2007c).

É importante considerar que os dados de erosão hídrica foram obtidos em rampa com comprimento de $11 \mathrm{~m}$ e declividade uniforme, cujas parcelas foram submetidas à chuva simulada com intensidade elevada e uniforme. Assim, a extrapolação desses dados para outros campos com características distintas e sob chuva natural com intensidade e duração variada deve ser feita com cuidado. É possível inferir-se, no entanto, que, provavelmente, os efeitos negativos das doses do dejeto estudadas sejam maiores em áreas com comprimentos e, ou, declividades de terreno maiores do que na área do experimento, em especial quanto às perdas de nutrientes. 


\section{CONCLUSÕES}

1. As perdas totais de solo e água por erosão hídrica não foram influenciadas pela dose de dejeto líquido de suínos aplicada sobre o solo cultivado com aveia, evidenciando, no entanto, influência do teor de água no solo antecedente às chuvas simuladas aplicadas.

2. Os teores de fósforo e potássio solúveis na água da enxurrada diminuíram após a aplicação de dejeto líquido de suínos no solo cultivado com aveia, por certo tempo; quando o cultivo foi submetido à chuva simulada, os teores reduziram das chuvas do teste 1 para as do teste 3 e aumentaram nas do teste 4 .

3. Os teores de fósforo e potássio solúveis na água da enxurrada diminuíram na dose $100 \mathrm{~m}^{3} \mathrm{ha}^{-1}$ de dejeto líquido de suínos aplicada sobre o solo para a dose $0 \mathrm{~m}^{3} \mathrm{ha}^{-1}$, nas chuvas simuladas dos testes 1 e 2 .

4. As perdas totais de fósforo e potássio solúveis na água da enxurrada não foram influenciadas pela dose de dejeto líquido de suínos aplicada sobre o solo no cultivo da aveia; no entanto, apresentaram tendência de diminuir nas chuvas do teste 1 para as do teste $3 \mathrm{e}$ aumentar naquelas do teste 4 .

5. Os teores de fósforo e potássio solúvel na água da enxurrada diminuíram exponencialmente com o aumento do número de teste de chuva simulada realizada em solo cultivado com aveia, em que os dados ajustaram-se significativamente ao modelo exponencial $\mathrm{y}=\mathrm{y}_{0}+\mathrm{ae} \mathrm{e}^{-\mathrm{bx}} ;$ o modelo não se ajustou aos dados da dose zero de dejeto em relação ao potássio.

\section{AGRADECIMENTOS}

À Fundação de Amparo à Pesquisa e Inovação do Estado de Santa Catarina (FAPESC), por parte dos recursos financeiros utilizados na pesquisa; $\mathrm{e}$ ao Centro de Educação Profissionalizante (CEDUP), Colégio Agrícola Caetano Costa, pela cessão da área experimental.

\section{LITERATURA CITADA}

ANDREOLA, F.; COSTA L.M.; MENDONÇA, L.S. \& OLSZEVSKI, N. Propriedades químicas de uma terra roxa estruturada influenciadas pela cobertura vegetal de inverno e pela adubação orgânica e mineral. R. Bras.Ci. Solo, 24:609-620, 2000.

ASSISTAT 7.6 Beta. Assistência Estátistica. Responsável Dr. Francisco de Assis Santos e Silva. DEAG-CTRN-UFCG, Campina Grande - PB, Brasil. Registro INPI 0004051-2. Disponível em: <http://assistat.com/indexp.html>. Acesso em: 30 jul. 2012 .

BADELUCCI, M. P. Infiltração de água e perdas por erosão em diferentes métodos de melhoramento da pastagem nativa. Porto Alegre, Universidade Federal do Rio Grande do Sul, 1997. 140p. (Dissertação de Mestrado)
BARBOSA, F.T. Comprimento crítico de declive relacionado à erosão hídrica, em diferentes tipos e doses de resíduo em duas direções de semeadura direta. Lages, Universidade do Estado de Santa Catarina, 2011. 99p. (Tese de Doutorado)

BARBOSA, F.T.; BERTOL, I.; WERNER, R.S.; RAMOS, J.C. \& RAMOS, R.R. Comprimento crítico de declive relacionado à erosão hídrica, em três tipos e doses de resíduos em duas direções de semeadura direta. R. Bras. Ci. Solo, 36:1279-1290, 2012.

BARILLI, J. Atributos de um Latossolo Vermelho sob aplicação de resíduos de suínos. Botucatu, Universidade Estadual Paulista, 2005. 77p. (Tese de Doutorado)

BERTOL, I.; ENGEL, F.L.; MAFRA, A.L.; BERTOL, O.J. \& RITTER, S.R. Phosphorus, potassium and organic carbon concentrations in runoff water and sediments under different soil tillage systems during soybean growth. Soil Till. Res., 94:142-150, 2007a.

BERTOL, I.; LEITE, D.; ENGEL, F.L.; COGO, N.P. \& PAZ GONZÁLEZ, A. Erodibilidade de um Nitossolo Háplico alumínico determinada em condições de campo. R. Bras. Ci. Solo, 31:541-549, 2007b.

BERTOL, O.J. Contaminação da água de escoamento superficial e da água percolada pelo efeito de adubação mineral e adubação orgânica em sistema de semeadura direta. Curitiba, Universidade Federal do Paraná, 2005. 209p. (Tese de Doutorado)

BERTOL, O.J.; RIZZI, N.E.; BERTOL, I. \& ROLOFF, G. Perdas de solo e água e qualidade do escoamento superficial associadas à erosão entre sulcos em área cultivada sob semeadura direta e submetida às adubações mineral e orgânica. R. Bras. Ci. Solo, 31:781-792, 2007c.

CASSOL, E.A.; LEVIEN, R.; ANGHINONI, I. \& BADELUCCI, M.P. Perdas de nutrientes por erosão em diferentes métodos de melhoramento de pastagem nativa no Rio Grande do Sul. R. Bras. Ci. Solo, 26:705-712, 2002.

CORRÊA, J.C.; BARILLI, J.; REBELLATTO, A. \& VEIGA, M. Aplicações de dejetos de suínos e as propriedades do solo. Concórdia, Embrapa Suínos e Aves, 2011. 18p. (Circular Técnica 58)

COSTA, A. Retenção e disponibilidade de água em solos de Santa Catarina: Avaliação e geração de funções de pedotransferência. Lages, Universidade do Estado de Santa Catarina, 2012. 302p. (Tese de Doutorado)

DAL BOSCO, T.C.; IOST, C.; SILVA, L.N.; CARNELLOSI, C.F.; EBERT, D.C.; SCHREINER, T.C. \& SAMPAIO, J.C. Utilização de água residuária de suinocultura em propriedade agrícola - estudo de caso. Irriga, 13:139-144, 2008.

DIETER, J. Poluição difusa por $\mathrm{P}$ devido à aplicação de água residuária da suinocultura sob condição de chuva simulada. Cascavel, Universidade Estadual do Oeste do Paraná, 2009. 51p. (Dissertação de Mestrado)

EMPRESA BRASILEIRA DE PESQUISA AGROPECUÁRIA EMBRAPA. Centro Nacional de Pesquisa de Solos. Manual de métodos de análise de solo. 2.ed. Rio de Janeiro, 1997. 212p. (Documentos, 1) 
EMPRESA BRASILEIRA DE PESQUISA AGROPECUÁRIA EMBRAPA. Sistema brasileiro de classificação de solos. 2.ed. Rio de Janeiro, Embrapa Solos, 2006. 306p.

GEBLER, L.; BERTOL, I.; RAMOS, R.R.; LOUZADA, J.A.S. \& MIQUELLUTI, D.J. Fósforo reativo: arraste superficial sob chuvas simuladas para diferentes coberturas vegetais. R. Bras. Eng. Agríc. Amb., 16:99-107, 2012a.

GEBLER, L.; LOUZADA, J.A.S.; BERTOL, I.; RAMOS, R.R.; MIQUELLUTI, D.J. \& SCHRAMMEL, B.M. Adaptação metodológica no cálculo de cargas contaminantes de fósforo em bacias hidrográficas gaúchas. R. Bras. Eng. Agríc. Amb., 16:769-776, 2012b.

HAYNES, R.J. \& SWIFT, R.S. Stability of soil aggregates in relation to organic constituents and soil water content. J. Soil Sci., 41:73-83, 1990.

INSTITUTO NACIONAL DE METEOROLOGIA - INMET. Rede de dados do INMET - Estação de Lages - SC. 2012. Disponível em: <http://www.inmet.gov.br/portal/ index.php?r=bdmep/bdmep>. Acesso em: 13 nov. 2012.

MORI, H.F.; FAVARETTO, N.; PAULETTI, V.; DIECKOW, J. \& SANTOS, E.L. Perda de água, solo e fósforo com aplicação de dejeto líquido bovino em Latossolo sob plantio direto e com chuva simulada. R. Bras. Ci. Solo, 33:189-198, 2009.

MURPHY, J. \& RILEY, J.P. A modified single solution method for determination of phosphate in natural waters. Anal. Chem. Acta, 26:31-36, 1962.

PELES, D. Perdas de solo, água e nutrientes sob aplicação de gesso e dejeto líquido de suínos. Curitiba, Universidade Federal do Paraná, 2007. 88p. (Dissertação de Mestrado)
PIERSON, S.T.; CABRERA, M.; LEVANYLO, G.K.; KUYKENDALL, H.A.C.; HOVELAND, S.; McCANN, M.A. \& WEST, L.T. Phosphorus and ammonium concentrations in surface runoff from grasslands fertilized with broiler litter. J. Environ. Qual., 30:17841789, 2001.

SCHICK, J.; BERTOL, I.; BALBINOT JUNIOR, A.A. \& BATISTELA, O. Erosão hídrica em Cambissolo Húmico alumínico submetido a diferentes sistemas de preparo e cultivo do solo: II. Perdas de nutrientes e carbono orgânico. R. Bras. Ci. Solo, 24:437-447, 2000.

SHARPLEY, A.N.; McDOWELL, R.W. \& KLEINMAN, P.T.A. Phosphorus loss from land to water: integrating agricultural and environmental management. Plant Soil, 237:287-307, 2001.

SILVEIRA, F.M. Perda de solo, água e nutrientes com aplicação de dejeto líquido bovino em Latossolo de textura franco argilo arenoso sob plantio direto e chuva natural. Curitiba, Universidade Federal do Paraná, 2009. 89p. (Dissertação de Mestrado)

SWANSON, N.P. A rotating-boom rainfall simulator. Trans. Am. Soc. Agron. Eng., 26:1738-1743, 1965.

TEDESCO, M.J.; GIANELLO, C.; BISSANI, C.A.; BOHNEN, H. \& VOLKWEISS, S.J. Análise de solos, plantas e outros materiais. 2.ed. Porto Alegre, Universidade Federal do Rio Grande do Sul, 1995. 174p.

WISCHMEIER, W.H. \& SMITH, D.D. Predicting rainfall erosion losses: A guide to conservation planning. Washington, USDA, 1978. 58p. (Agricultural Handbook, 537) 